\title{
Study and Performance Improvement of the Drive Systems for a Class of Machine Tools
}

\author{
Mikho Mikhov ${ }^{1, *}$ and Marin Zhilevski ${ }^{1}$ \\ ${ }^{1}$ Faculty of Automatics, Technical University of Sofia, Bulgaria
}

\begin{abstract}
This paper deals with some problems in the modernization of a type of machine tools with multi-coordinate drive systems. The basic requirements to the drives of each coordinate axis and the spindle are presented. Using the analysis carried out, a practical approach to appropriate selection of the respective drives is applied. The methodology offered is illustrated with some examples for choice of drives with direct current and alternating current motors. Some experimental research of cases with different feed and spindle drives are described and discussed. Better capabilities of the modernized machines for processing more complex workpieces are achieved, at a relatively low price. This research and the obtained results can be used in the design and tuning of electric drives for the considered type of machines with numerical program control.
\end{abstract}

\section{Introduction}

Machine tools are used for processing of workpieces with various geometrical shapes. Typically, several kinds of machines with different configurations are required to process complex workpieces [1-3]. The modernization of a type of machine tools with numerical program control includes introducing a rotary table for angular position of the workpieces and a specialized device for spline channels with the goal of achieving more flexibility of mechanical processing. The modernized machines allow for the following operations: milling, drilling, boring and processing of spline channels.

The main problems considering the modernized machines are: selection of appropriate drives for the respective axes and the spindle; development of control procedures; creation of the required software for coordination of the operations; improving their performance and productivity; reducing of the energy consumption; achieving of higher reliability; extending the operational life.

Different mechanical operations place high demands on the electric drive system, requiring an optimal selection of motors, power converters, sensors and mechanical gears. The drive system of the studied machine tools includes feed drives, a spindle drive and auxiliary drives.

The feed drives are used for fast and accurate moving of the tools and the workpieces to the respective positions $[4,5]$. The spindle drives participate in the workpieces production

*Corresponding author: mikhov@tu-sofia.bg 
and greatly affect the quality and performance of the entire machine $[6,7]$. The auxiliary drives are used in the additional systems and mechanisms that serve the proper operation of the machine tools. In some cases, the introduction of appropriate auxiliary drives significantly improves the performance, accuracy, economy and cost. It can also provide mechanical machining of workpieces with more complex geometric shapes.

Various variants with direct current (DC) and alternating current (AC) motors are applied in the drive systems for machine tools. Computer modeling provides a very good opportunity to study in detail the behavior of these systems in various transient and steady state operating modes, which is not always convenient or possible in industrial and laboratory conditions.

The basic requirements for the drive system are formulated and described in this paper. Also, an algorithm for selection of the respective electric drives is presented. Some examples for choice of feed and spindle drives with DC and AC motors are shown. They illustrate the practical application of the used algorithm. Simulation and experimental results are presented and discussed. The application of the modernized machines is illustrated with the making of a specific workpiece.

\section{Drive system selection}

Fig. 1 represents the block diagram of a drive system for the modernized machines. The notations are as follows: PCD - program control device; ED1 - ED10 - electric drives; G1 G8 - mechanical gears; L1 - L8 - loads.

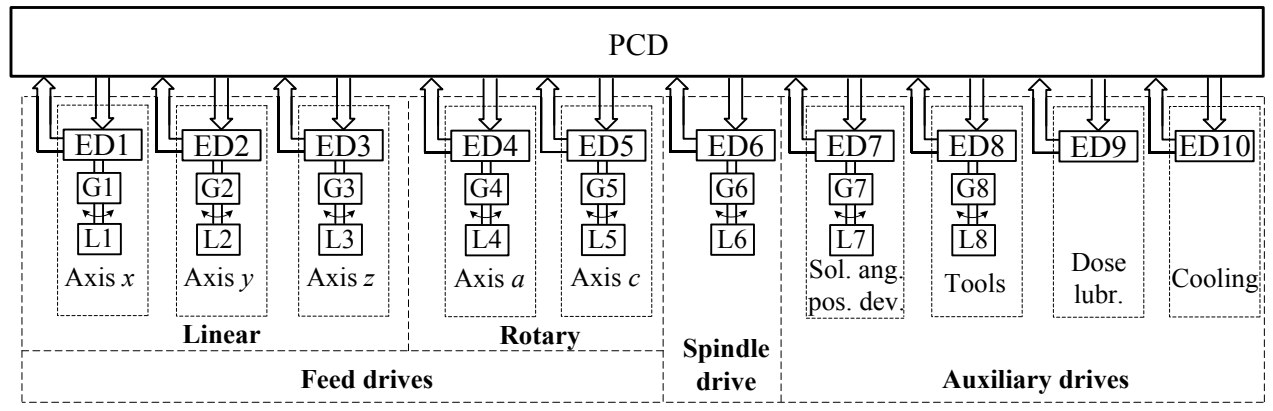

Fig. 1. Block diagram of the drive system.

The feed drives are applied for positioning of both the tools and the workpieces at the respective positions and they partake in the machining process. The following requirements to them can be formulated [8]: speed control in a wide range; good dynamics; high positioning accuracy; realization of the needed movement cycles; providing the required torque; reversible speed and torque regulation; compensation of the disturbances; convenient maintenance; reliability. The introduced rotary table has two coordinate axes: a - with tilting of $0^{\circ} \div 90^{\circ}$ and $\mathrm{c}-$ with rotation of $0^{\circ} \div 360^{\circ}$. An improved structure for such rotary table is described in [9].

The spindle drive should meet the following requirements [10]: dual-zone speed control (by constant torque and constant power); high maximum speed; oriented braking; reversible speed regulation.

The basic requirements to the auxiliary drives can be described this way [8]: angular positioning of the workpiece with desired accuracy; subsystem providing choice of the necessary tools; lubrication of the machine axes; appropriate cooling subsystem.

The design process of the drive system has the next basic stages: development of a methodology for selection of electric drives (motors, power converters, sensors and 
mechanical gears); calculations related to the methodology procedures; detailed analysis of the respective versions; modeling and computer simulation of the transient and steady state regimes; experimental study to estimate the qualities of the selected electric drives.

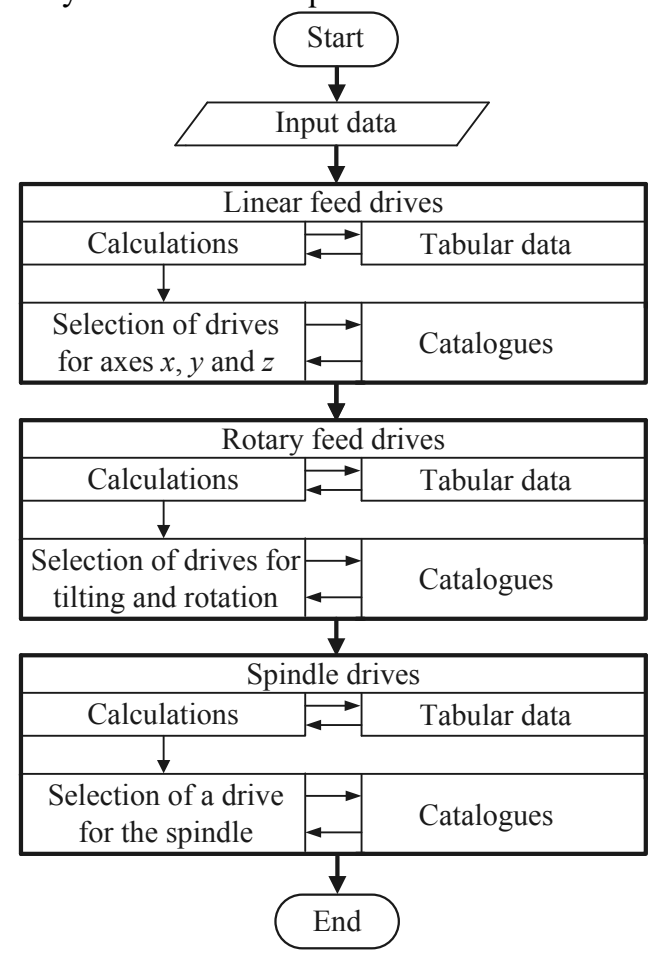

Fig. 2. Block diagram of the algorithm for drive system selection.

Fig. 2 presents a simplified block diagram illustrating the selection methodology. The input data includes the heaviest cutting regimes, the material hardness, some parameters related to the machine and the tools used. The tabular data are taken from companies producing tools, mechanical gears and guides [11-13].

Table 1. Some results for the selected electric drive system.

\begin{tabular}{|c|c|c|c|}
\hline Elements & Linear feed drives & Rotary feed drives & Spindle drive \\
\hline $\begin{array}{c}\text { Mechanical } \\
\text { gear }\end{array}$ & $\begin{array}{c}\text { ball screw with diameter } \\
0.04 \mathrm{~m} \text { with step } 0.02 \mathrm{~m}\end{array}$ & $\begin{array}{c}\text { worm gear with coefficients: } \\
g_{a}=3^{\circ} / \mathrm{rev} \text { and } g_{c}=2^{\circ} / \mathrm{rev}\end{array}$ & $\begin{array}{c}\text { mechanical gear } \\
\text { with ratio }=1.3\end{array}$ \\
\hline Motor & $\begin{array}{c}\mathrm{DC} \text { motor 3PI12.18: } \\
M=7 \mathrm{Nm}, \\
\omega=209.34 \mathrm{rad} / \mathrm{s}\end{array}$ & $\begin{array}{c}\text { - for axis } a: \text { synchr. motor DS4-1-6: } \\
\begin{array}{c}\text { for axis } c: \text { synchr. } \text { motor DT3-1-10 } \\
M=0.94 \mathrm{Nm}, \omega=628 \mathrm{rad} / \mathrm{s}\end{array}\end{array}$ & $\begin{array}{c}\text { AC motor DH: } \\
P=10 \mathrm{~kW}, \\
\omega=523.4 \mathrm{rad} / \mathrm{s}\end{array}$ \\
\hline $\begin{array}{c}\text { Power } \\
\text { converter }\end{array}$ & SA-12 & $\begin{array}{c}\text { - for axis } a: \mathrm{KW} 2 ; \\
\text { - for axis } c: \text { KW2 }\end{array}$ & $\mathrm{KW} 10$ \\
\hline Sensor & encoder & $\begin{array}{c}\text { - for axis } a: \text { resolver; } \\
\text { - for axis } c: \text { resolver }\end{array}$ & resolver \\
\hline
\end{tabular}

Methodologies for selection of spindle drives, linear and rotary feed drives for different mechanical operations are presented in [8-10], $[14,15]$. The catalogue data are obtained from the some manufactures of motors, power converters, sensors and mechanical gears [16-20]. 
In practical selection of drive system for the studied class of machine tools, detailed calculations have to be carried out in the heaviest processing regimes for the respective mechanical operations. In this case, the heaviest cutting regime is in machining of alloyed steel. On this basis, in Table 1 are shown some of the obtained results.

\section{Study of the drive system}

The used approach includes: analysis of the different options for the feed and spindle drives; computer modeling of the operation regimes; optimization and tuning of the control loops; coordination of the drives for processing of the respective workpieces; practical study of the modernized machines to evaluate their qualities.

A block diagram of the stand for experimental research of electric drives is presented in Fig. 3, where the notations are as follows: PC - personal computer; CU1, CU2 - control units for the tested electric drive and the load system; PC1, PC2 - power converters; M1, M2 - motors; SS - speed sensor; CP - control panel; CC current controller; BMV - block for measurements and visualization.

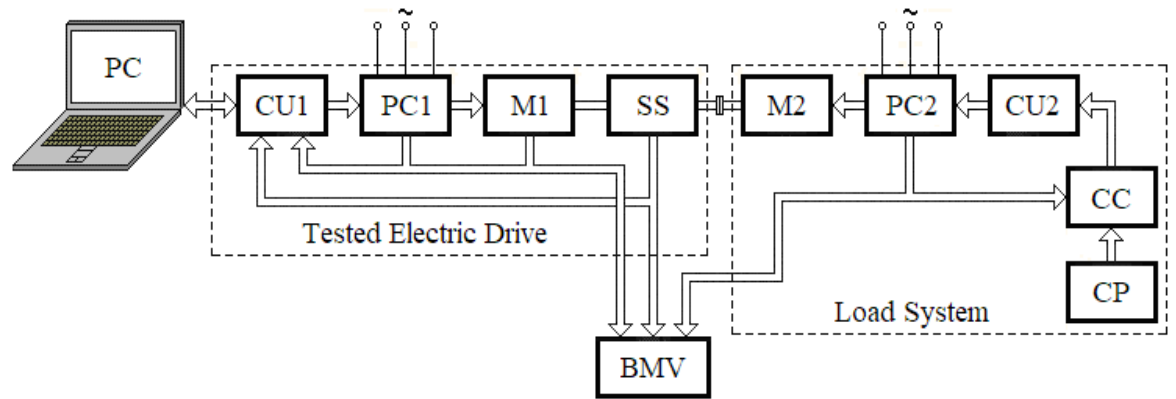

Fig. 3. Block diagram of the stand for experimental research of electric drives.

Some simulation and experimental results for the electric drives of the studied class of machine tools are presented in the next figures.
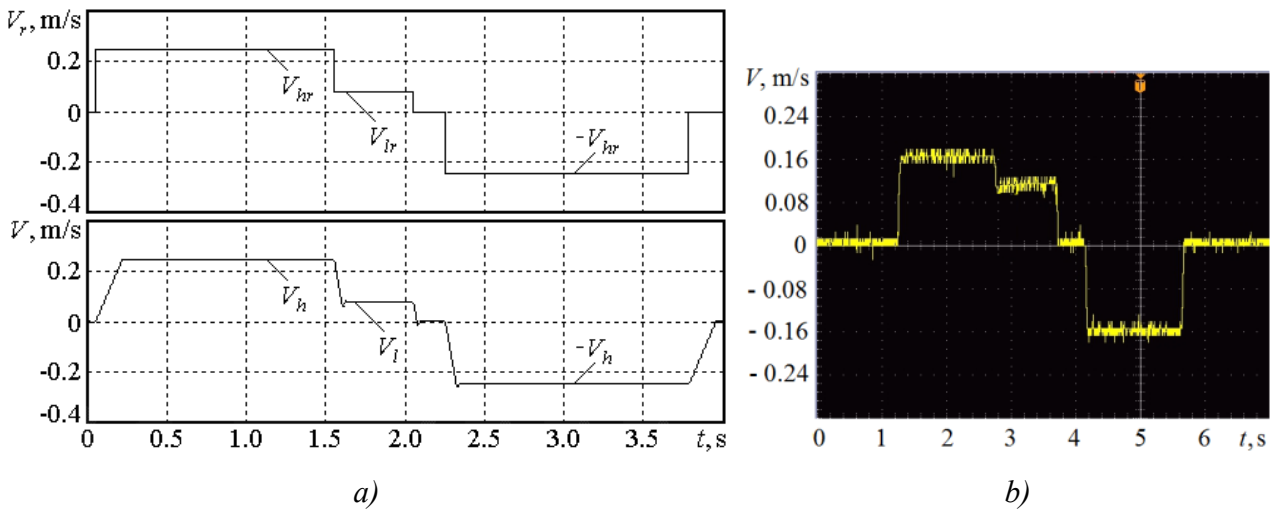

Fig. 4. Results from the study of electric drives for linear axes.

Fig. 4a presents time-diagrams from computer simulation of a brushless motor drive. In this case the reference high speeds in both directions are $V_{h r}= \pm 0.25 \mathrm{~m} / \mathrm{s}$, and the reference low speed is $V_{l r}=0.08 \mathrm{~m} / \mathrm{s}$. Fig. $4 \mathrm{~b}$ shows an experimental obtained oscillogram of the implemented DC drive for a linear axis at the respective set speeds. 
Time-diagrams from the study of electric drives for the rotary axis and the spindle are presented in Fig. 5.

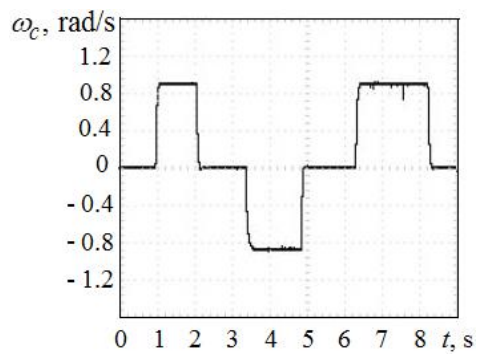

a)

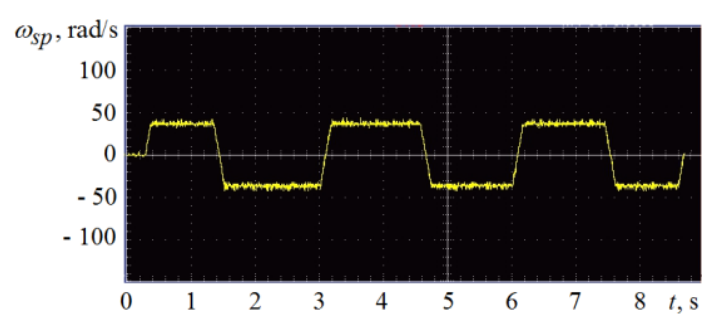

b)

Fig. 5. Time diagrams of electric drives for the rotary axis and the spindle.

\section{Practical application}

The practical application of a modernized machine with numerical program control is illustrated by the coordination of the respective drives for the production of a specific workpiece with a number of mechanical operations. Fig. 6 presents the 3D drawing of this workpiece.

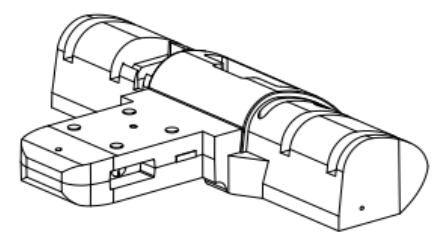

Fig. 6. The 3D drawing of a workpiece.

Fig. 7 illustrates the machining process and the finished workpiece. Fig. 7a presents a boring operation, and fig. $7 \mathrm{~b}-\mathrm{a}$ drilling operation. The processed workpiece is shown in Fig. $7 \mathrm{c}$.

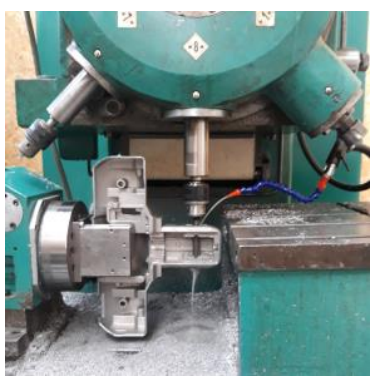

a)

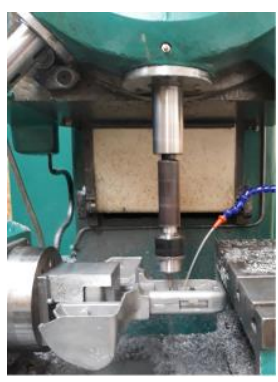

b)

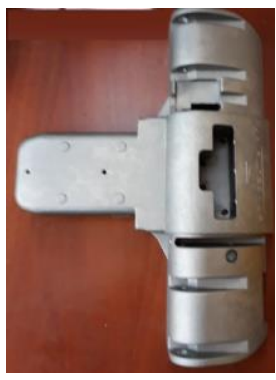

c)

Fig. 7. Boring and drilling processes and the respective finished workpiece.

\section{Conclusion}

Basic problems in the modernization of a type of machine tools with multi-coordinate drive systems are discussed in this paper. On this basis, an algorithm for drive choice selection is presented. Some examples for selection of electric drives with DC and AC motors are described. 
Higher productivity and better capabilities of the modernized machines to process more complex workpieces are achieved, at a comparatively low price. An example for coordination of the feed and spindle drives in the production of a workpiece with application of several different mechanical operations is presented.

The reported study and the obtained results can be applied in the design and tuning of the respective drives for the considered type of machine tools with numerical program control.

This research was funded by the Technical University of Sofia, Bulgaria under Project No. 191PR0002-08/2019.

\section{References}

1. D. A. Stephenson, J. S. Agapiou, Metal Cutting, Theory and Practice (CRC Press, 2006)

2. H. Youssef, H. El-Hofy, Machining Technology: Machine Tools and Operations (CRC Press, 2008)

3. I. P. Girsang, J. S. Dhupia, Machine tools for machining, (Springer-Verlag, 2015).

4. Y. Altintas e al, A. Verl, C. Brecher, L. Uriarte and G. Pritschow, Machine Tool Feed Drives, CIRP Annals - Manufacturing Technology, 60 (2011)

5. D. Hirabayashi, T. Yamazaki, Reduction of vibration for feed drive system using linear motor at high-speed driving, J. Phys.: Conf. Ser. 1065 (2018)

6. M. Mikhov, M. Zhilevski, Analysis of a Multi-Coordinate Drive System Aiming at Performance Improvement, Proc. Int. Conf. Res. Dev. Mech. Ind., 2, (SaTCIP, 2012)

7. D. Mu, X. Wang, Application of High-speed Spindle in Intelligent High-speed Drilling and Tapping Center Machine Tool, IOP Conf. Ser.: Mater. Sci. Eng. 493 (2019)

8. M. Zhilevski, M. Mikhov, Optimal selection of feed drives for boring machines, IOP Conf. Ser.: Mater. Sci. Eng. (to be published)

9. M. Zhilevski, M. Mikhov, Study of Electric Drives for Rotary Table of Milling Machines, J. Multidisc. Eng. Sci. Techn., 2 (2015)

10. Zhilevski M., M. Mikhov, Study of Spindle Drives for Boring Machines, MATEC Web of Conferences, 287 (2019)

11. Sandvik Coromant, Metalcutting Technical Guide: Turning, Milling, Drilling, Boring, Toolholding, (2005)

12. SKF Group, Precision Rolled Ball Screw, Catalogue (2013)

13. SKF Group, Rolling bearings, Catalogue (2018).

14. M. Zhilevski, M. Mikhov, Methodology for selection of feed drives for milling machines, Proc. Techn. Univ. Sofia, 64 (2014)

15. M. Zhilevski, M. Mikhov, Optimization of the Drive System Choice for a Class of Drilling Machines, Eur. J. Electr. Comp. Eng., 2, pp. 12-16 (2018)

16. AMKASYN, AC Servo- and Main Spindle Motors, Catalogue (2014)

17. AMKASYN, Servo Drives $K E / K W$, Catalogue (2014)

18. SERVOMOTORS, Gama Motors, Catalogue (2016)

19. Graphical Peripheral Devices, Sensors, Catalogue (2017)

20. DYNASYN, Servo Motors DT and DP, Catalogue (2014) 